Doctor Eduardo Moore

\title{
Causas que producen la degeneración de la raza
}

(Nolas seleccionadas de la Conferencia de Extensión Universitaria que el doctor Eduardo Moore dictó en Concepción el 9 de Junio de 1923).

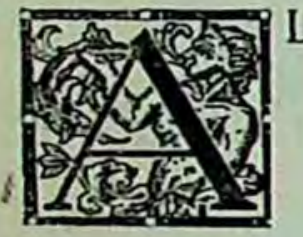

L iniciar este año las Conferencias universitarias, la Facultad de Medicina eligió, como tema de la primera, el más serio de todos los problemas que debe ocupar la atención de los ciudadanosaquel que fué declarado en el Congreso de todas las Sociedades de Cruz Roja del mundo, reunido en Cannes en 1920, como el asunto más importante de cuantos puede ocupar, en la actualidad, la atención de los poderes públicos: me refiero al relacionado con las enfermedades de trascendencia social.

La postergación en la solución de este problema está causando perturbaciones tan intensas en la salud pública, que ya constituye un factor definitivo de degeneración de la raza, de disminución de los nacimientos, de aumento considerable de enfermedades que suministran la inmensa mayoria de los pobladores de los Hospitales. Dispensarios. Casas de Huérfanos, principalmente de los Manicomios y de las Cárceles.

La desorientación del individuo tendiente a perturbar la sociedad, no sometiéndose a los códigos morales establecidos por ella, sembrando discordias o utopías, o cediendo al influjo de malvados o de histéricos, es producida en la mayoría de los casos, por individuos que no han limpiado su sangre de los espiroquetes que producen la plaga roja.

Este grave problema se resuelve, educando, previniendo y curando, o en otros términos: 1. enseñando las funciones de la vida, es decir la Fisiologia, que instruye lo mismo sobre las funciones del cerebro, corazón. pulmones, etc., que sobre las de la reproducción: $2 .^{\circ}$ previniendo y evitando el contagio por estos males y $3 .^{\circ}$ curando las enfermedades.

Ha llegado la época en que los padres de familia, y los maestros, enseñen a la juventud las funciones de su propia vida, y los peligros a que se exponen los que no se respetan a si mismos, los que olvidan la moralidad y hacen tabla rasa de su salud. 
La mujer es el elemento conservador de las sociedades. forma el hogar. oásis de descanso y vivificación en el desierto de la vida. Y aquellos que por espiritu diablezco, por sobresalir entre los demás, hacen frases irónicas cuando se trata de la mujer, caen. sin embargo. en una meditación prolunda al pensar la felicidad que los embriaga cuando tienen delante de sí la imagen de su madre que les dió la vida, que la saben pura, inmortal, porque ellos no son sino la continuación de la vida de ella. Mujeres son sus hermanas a quienes ayudan y vigilan con ternura, que ellas les devuelven con creces. mujer la madre de sus hijos. Mujer la hija que endulza los sinsabores de las luchas cotidianas, y reeduca a los padres con sus gracias y alegrías, haciéndolos más humanos y benévolos. Si tomamos en cuenta que maestras y nodrizas completan el círculo lemenino que rodea al hombre toda su vida, y que desde la adolescencia su afán incesante es el ideal, al que le rinde los homenajes de una diosa, habremos concluído que nada ocupa más la mente del hombre que la mujer: entonces, debemos dignificarla, elevarla e instruirla.

La madres de familia que me escuchan, van a convencerse que estoy en muy buena compañia, al declararles que es un anhelo universal el que existe en todos los paises, de dar instrucción a la mujer sobre las funciones de la vida, porque la mujer instruida es el factor más importante en la resolución del problema que nos ocupa.

El Dr. Carrol, representante de una Oficina de Salud Pública, refiere el resultado de una entrevista celebrada con el Cardenal Gibbons, el más grande de los Obispos católicos de los Estados Unidos, y una de las más grandes eminencias del orbe. llamado el segundo Pontifice.

El Dr. Carrol, católico también. halló oposición a su obra entre personas de su propia fe y se dirigió al Cardenal Gibbons para inquirir si estaba o no justificado el continuar dando instrucción sobre los problemas que enseñan a conocer el sexo y las enfermedades venéreas a jóvenes de ambos sexos, por médicos del mismo sexo.

- ¿Por qué no, contẹstó el Cardenal Gibbons. Sabe usted como médico, que esas enfermedades existen. Su deber es combatirla con sus recursos como médico. como es igualmente el mío combatirlas como sacerdote. Son enemigos, y no es posible luchar contra un enemigo en la oscuridad.

- ¿A qué edad cree su Eminencia que debe darse tal instrucción?-Volvió a preguntar el doctor Carrol. Y sin vacilar contestó el Cardenal Gibbons:- .En la edad de la pubertad. En dicha edad el instinto sexual comienza a manilestarse: así es que a esá edad la instrucción apropiada puede darse, y la que conduce a ese punto puede empezarse antes».

La instrucción primordial que exigimos, es el estudio de la Fisiología, ciencia que nos enseña a conocer las funciones, una a una, de los distintos órganos de que se compone el cuerpo humano normal, las que dan la vida y movimiento al individuo, y también enseña otras funciones de una importancia mayor. más elevada aún que las otras, son las funciones de la reproducción; funciones que llegan al 
organismo para que éste las reciba, las alimente, las mantenga adormecidas hasta la pubertad a fin que más tarde sean las de la conservación de la especie, única inmortalidad visible para los humanos, ya que los padres no mueren nunca, sino que continúan su vida en sus hijos a través de la mujer, que es la cuna de la humanidad. La enseñanza de la Fisiologia se hace en Chile, sólo en la Escuela de Medicina destinada a los estudiantes, en el Instituto de Educación Física, muy limitada en las Escuela de Dentística y de Matronas y en la Escuela Libre que llamamos de Altos Estudios que funciona en el Museo Nacional, destinada a un perso nal que ya tiene una educación científica previa.

En el resto del país no se enseña esta ciencia, porque no puede llamarse así, la que se dá en los Liceos y al final de los estudios y en cuyas cátedras se pasa como por sobre ascuas candentes, sin siquiera mencionar las funciones de la reproducción. Sin embargo. con esta clase de estudios no sólo nos damos cuenta de la marcha normal de nuestra vida, sino que nos damos cuenta de las enfermedades que no son otra cosa que las funciones perturbadas, es decir. la Fisiologia exagerada: y de la Higiene que es la Fisiologia aplicada.

Hace más de 50 años, uno de los más grandes pensadores de la humanidad. Herbert Spencer, el sabio que desarrolló en el terreno filosófico y sociológico la teoría de la evolución, antes que Darwin en el terreno biológico, estableció que el orden de los conocimientos que deben procurarse a los educandos serian: 1. Fisiología: 2. Conocimientos necesarios para llegar a adquirir una profesión u oficio: $3^{\circ}$ Los conocimientos que nos permiten conocer a los demás: la Sociologia: y $4 .^{\circ}$ Los conocimientos que adornan y recrean el espíritu: Música. Pintura. el arte en general.

Pero estos estudios no servirian de nada, si ante todo no conocemos las funciones de la vida para poder conservarnos.

El enorme prejuicio de los padres, y su ignorancia manifestada en la repulsión para instruir a sus hijos en la ciencia de la vida, son causa de las tragedias diarias que observamos en todos los hogares, cualesquiera que sea la clase social. El profesor Pinard de la Facultad de Medicina de París, tratando de la manera de instruir a sus hijos decía: Hemos hablado tanlo y en tal forma de órganos vergonzosos, que yo mismo he titubeado hablar a mis hijos sobre estas cuestiones. y me he sentido satisfecho de tener yernos médicos, por intermedio de los cuales he podido darles esa instrucción. Llamar vergonzosos a los órganos que nos han dado la vida, es incomprensible.

Corresponde en especial enseñar Fisiología a toda persona que aspire al magisterio: porque todo maestro debe iniciar estos conocimientos. para lo que debe estar muy bien preparado.

Creemoś llegada ya la hora de que en la instrucción primaria y secundaria. no se siga prescindiendo de la fecundación de las plantas, del conocimiento de los fenómenos grandiosos de la reproducción, y esta ignorancia alcanza a la del hombre. ¿¿Cuál es la razón de esta ocultación? - se preguntaba la doctora Raquel Camaña, perdida tan prematuramente para la ciencia de la República Argentina.-El núcleo del mal que tratamos, decía. está en el prejuicio del pe- 
cado, en esa absurda denominación de órganos y funciones vergonzosas; en esa reacción cristiana-útil dique en sus comienzos, que detuvo la ola corrompida de la civilización pagana-pero que, llevada a exageraciones perjudiciales, nutrió el error lunesto de creer que el pudor consiste en la ignorancia.,

Sin las informaciones de padres o maestros y excitada la curiosidad por la atracción del misterio. los jóvenes tratan de procurárselas por los medios modernos a su alcance, que son tantos y tan variados dadas las oportunidades. que en estos tiempos se proporcionan fáciles y muy frecuentes. Los bailes excitantes, el flirt. las malas compañías, el cinematógrafo, el teatro, los libros y revistas eróticas, las imprudentes preguntas de representantes de algunas religiones en las que no se establece sin embargo, en su moral que se torture el alma de inocentes. sino que dé sabios consejos a los que sean exaltados por estas dudas. y por fin la prostitución que sostienen las Municipalidades y los que con ella especulan, como ser propietarios que obtienen pingües rentas, hasta algunas policias y políticos. Es en estas fuentes en donde han obtenido los jóvenes las primeras nociones sobre la naturaleza y significado del instinto que comienza a manifestarse.

No nos extrañemos entonces que sobrevenga las taras que más tarde se traducirán en prácticas viciosas, en enfermedades tenaces y que si no se les pone pronto remedio, perdurarán toda la vida.

Ningún libro es más recomendable después de saber Fisiologia, que el libro de Augusto Forel, catedrático de Psiquiatría en la Universidad de Zürich, intifulado la Cuestión Sexual, escrito en alemán. Irancés, español y al alcance de maestros y alumnos de cualquiera preparación.

Cuando se empapa el educando con la elevada enseñanza de Forel le es Tácil convencerse que, el amor y la vida sexual con sus leyes, están en relación estricta con la que gobierna nuestro equilibrio individual psíquico y físico. así como con las leyes que dominan el equilibrio social y la evolución histórica de los seres y de los pueblos; que la mujer desempeña un rol capital en la estabilidad social y en el progreso de las civilizaciones; que los misóginos (odio a la mujer) son anómalos sexualmente, o son ecos inconscientes de juicios misogénicos: que la ignorancia de la vida sexual es la causa de desorientación moral, de desapego a la vida, de caídas y de enfermedades sociales, porque afectan a la moral social.

El conocimiento de la vida sexual y sus leyes, del amor y de las suyas. es más necesario que el de todo otro conocimiento de Fisiología. de Psicologia o de Sociologia; conocer la sexualidad es conocer la moral, porque la cuestión sexual es una cuestión moral, es conocer la facultad que posee la voluntad humana de disponer de la función sexual, es prevenir, aliviar, tranquilizar de los sufrimientos e infortunios intimos, favoreciendo la felicidad individual. La naturaleza-a pesar de todas sus imperfecciones-está plena de bellezas y de objetos de goces. siempre que se la sepa comprender. Si el hombre se viera privado del amor, de la necesidad sexual. y de las consecuencias que de esto se deriva bajo el punto de vista mental, perdería casi toda la poesía y el carácter moral y no tendría objeto la vida: porque la vida sexual es el cimiento de la creación. de la propiedad y de la familia. despierta las 
cualidades altruistas, la abnegación, la ternura, la paciencia, la dulzura, el sentimiento del deber, el amor al prójimo, y las elevadas comprensiones de la estética.

La mujer, cualquiera que sea su situación social, está ávida de saber y no hay padres, no hay prejuicios, no hay modas que detengan al mandato de una hija cuando lo que desea es de colocarse en condición superior.

El Delegado de Suecia doctor Marcus a la Liga de las Sociedades de Cruz Roja, reunida en Copenhague el 20 de Mayo de 1921, dá cuenta que desde que Suecia se puso en campaña contra las enfermedades sociales, reconoció en el acto, la importancia de una educación popular sistemática. Un párralo especial de la ley menciona expresamente que el Estado está encargado de un servicio de educación sobre las cuestiones propias del sexo. Los primeros conocimientos de Biologia, de Zoologia y de Higiene deben preparar al niño a la instrucción sexual, llevándolo insensiblemente con gran tacto hasta los 15 años. Esta enseñanza pueden darla médicos o pedagogos. En Inglaterra la educación en Higiene sexual es la mayor de las armas de combate contra las enfermedades. llamadas ssociales, porque el estado social las mantiene y ellos roen la sociedad.

Es el Ministerio de Higiene de Gran Bretaña el que dirige la enseñanza de Higiene Social y lo confía a las autoridades locales, ayudadas por el sinnúmero de sociedades filantrópicas. Se extienden estos conocimientos a todas las mentalidades: aún a los médicos, a todos los gremios. En ese país donde el tratamiento de estas enfermedades es enteramente voluntario, la obra educativa persigue en primer lugar persuadir a las personas recurran a los Dispensarios en donde se les dá tratamiento y medicamento gratuito y en segundo lugar a excitar todos los medios de acción que pueden impedir la diseminación de la enfermedad entre las personas que están todavia intactas.

El gobierno de los Estados Unidos, desde 1918 empezó una campaña enérgica en bien de la instrucción de las niñas en materia que enseña las funciones de su sexo.

Esta enseñanza debe darse en la escuela por sus mismas maestras, que tienen tacto innato.

En las escuelas superiores de instrucción secundaria el maestro debe ser del mismo sexo. No debemos olvidar que debe someterse a los pedagogos a un examen de Fisiología y de Higiene Social, antes que se dediquen a trasmitir estos conocimientos a sus educandos, a fin de calificar su tino y discreción al desarrollar estas materias, porque no se puede confiar estos delicados problemas sino a los que los enseñen con el más alto idealismo, eliminando toda enseñanza que no conduzca al objetivo. El profesor es el que crea la fe en la necesidad del conocimiento, y el que podrá mantener viva la sed de saber.

El Gobierno de los Estados Unidos, por intermedio de su Servicio de Higiene Pública, ha emprendido tambiên otra campaña educativa dirigida a los jóvenes para preservar la raza contra las enfermedades venéreas, exigiendo educación en todos los establecimientos de enseñanza empezando por aclarar en los estudios las funciones más nobles, las que producen la vida, y estableciendo en la mente de los niños, las ideas grandiosas de la responsabilidad sexual como gene- 
radores de esa vida que tendrán que darla tarde que temprano y que están obligados a asegurar para su patria hijos sanos. El Gobierno ha hecho publicar profusamente un folleto, intitulado .El Problema de la Educación Sexual en las Escuelas, $y$ en donde se puede leer en el capítulo denominado .El Sistema Antiguo, lo siguiente: .Los niños son, naturalmente curiosos observando los hechos - de la reproducción. Sólo un niño anormal puede crecer sin un interés vívido - en el maravilloso drama de la renovación de la vida que ve a su alrededor, y - sin experimentar los impulsos y emociones naturales de la adolescencia. En el - vasto sistema subterráneo de educación actual, institutrices ignorantes, grupos de - amigos mal hablados y amorales, consejos de charlatanes. falsedades y avisos - de medicinas patentadas, peliculas eróticas y aventuras personales, son sus pro- fesores?.

De lo que se deduce esta primera ley: Una inmensa mayoria de niños, adquieren su primera impresión sobre el sexo, de fuentes impropias y antes que estos niños lleguen a los 12 años de edad.

En 637 niños, muy bien examinados, por el doctor Exner observó que la primera impresión permanente sobre sexo la habian recibido, término medio. a los $91 / 2$ años, y que en algunos empezó a los 4 ó 5 años. la mayoría entre 10 y 11. y algunos entre 14 y 15 .

Al lado de ese estudio publica que en 727 otros hombres, recibieron la primera instrucción propia sobre sexo de fuentes determinadas. padres. maestros, sacerdotes, término medio a los $151 / 2$ años, habiéndose dado tal instrucción entre 6 hasta 25 años.

El doctor Exner encontró que el $91 \%$ de colegiales educados en escuelas de ambos sexos habian recibido su primera impresión sexual de fuentes indeterminadas de mal origen, y el $79 \%$ le contestó que tenian mala impresión de esos recuerdos. En cambio un $951 / 2 \%$ tenian muy buena idea de haber recibido la primera impresión de sus padres, maestros. lecturas de folletos científicos u otra fuente conocida. Hay pues, una gran responsabilidad en los padres. cuando estallan vicios prematuros o enfermedades sociales.

Enseñarles los procesos de la reproducción y desarrollo ulterior del hijo. lo que es el matrimonio. la prostitución. las enfermedades venéreas, la ilegitimidad y la higiene, etc., en estudios lentos y continuados para que se graven ideas de educación sobre la maravilla de la reproducción. de formar para ellos mismos la vida, pensando en el matrimonio que es una de las relaciones más sagradas de la existencia.

Los oficiales de sanidad, que están en contacto directo con los enfermos de males sociales han inducido a la autoridad que lo primordial en la lucha contra estas enfermedades es la instrucción sexual a los niños y a las niñas antes de los 13 años. cuyas almas buenas y bien dispuestas son una pasta blanda para modelar con ella cualesquiera escultura hermosa.

Conocemos Estado por Estado de los Estados Unidos el movimiento seguido hasta el dia. como consecuencia de esta obra educativa, la que ha dado legislación, enseñanza y curación apropiada: hay 48 Estados. 3 territorios y un 
Estado federal, que suman 52. de ellos en 43 se declara que las plagas venéreas son contagiosas y peligrosas para la salud pública, 35 declaran culpable al que infecta, 43 autorizan el examen de los portadores sospechosos. 29 ordenan a los sanitarios a suprimir la prostitución, pero, otros Estados 13 por un método y 39 por otro tienden a la supresión absoluta, es decir los 52 Estados, 38 Estados exigen la declaración obligatoria de la enfermedad, expresando el número de enfermos. pero 7 exigen el nombre, 25 Estados tratan a los enfermos gratuitamente.

En estos momentos S. M. la Reina de los belgas, se ha puesto a la cabeza de un movimiento nacional para desarraigar las enfermedades venéreas en su pais.

A fines de 1921 el primer Congreso anti-venéreo Dan Americano que se reunió en Wáshington tratando de la lucha anti-venérea, dejó establecido que la educación sobre cuestión del sexo era el asunto más imporlante y urgente de la lucha, y fijó el programa general de esta enseñanza.

\section{PROFILAXIS O PREVENSIÓN DE LOS MALES. 2.0 TEMA}

1. Curar los enfermos atacados de males sociales, para que no contagien a los sanos es la mejor prevención, y se procura sembrando Dispensarios gratuitos.

2. La educación es un asunto trascendental y útil en la profilaxis.

3. La tercera medida es la propaganda, con tal que sea eficaz.

En el Primer Congreso Médico reunido en Santiago en 1900, propusimos una Liga contra la sífilis sin obtener ningún resultado; perseveramos en la cátedra y conseguimos que los estudiantes aceptaran entusiastas las ideas expuestas. y como cada médico es un Profesor de sus clientes la obra no fué perdida, y tengo la satisfacción de haber escuchado hace unos cuantos dias, a uno de ellos. médico que es una gran esperanza para la medicina, decirme: saquellas ideas que usted sembró en su clase, me sirvieron desde esa época para regularizar mı conducta, para interesarme vivamente en el problema, como para tratar a mis clientes.

4. En la profilaxia entra la prostitución, problema embrollado para los médicos, que no deben mezclarse en otra cosa, que en contribuir a la abolición absoluta. sin limitaciones.

Es esta una institución que avergüenza a la humanidad, ha sido creada por el hombre pagano que miraba la mujer como un mueble, fué elevada por Napoleón I a la categoría de institución pública reglamentada, se ha mantenido en los paises cristianos, no por consejo de los médicos, sino por el error tan repartido. que con esta institución reglamentada por los municipios se obtenian beneficios para la salubridad y moralidad pública. Se creía que disminuian los crimenes, porque las policías localizando las casas, supervigilaban estos centros de los crimenes: que acorraladas y vigiladas se podía tener el control de las mujeres y facilitaba la reducción del número de ellos; que se podía controlar el 
tráfico del alcohol en conexión con la casa de tolerancia: que se podian prevenir los crimines o atentados contra las mujeres honradas: que se protegía a la comunidad de la proximidad o promiscuidad con estas infelices; que cortaba la explotación que se hace de estas desgraciadas por las patronas o caftens, y que disminuian las enfermedades venéreas por intermedio de la inspección médica: que se aminoraba el número de asiladas a causa de la reglamentación que se protegia a la juventud del contacto con ellas en las calles, que prevenía a la población masculina de las perversiones o anomalias sexuales, proporcionándoles medios naturales, etc., etc. Pero la experiencia ha demostrado otra cosa. como vamos a demostrarlo:

Lejos de beneficiarse la salubridad, se agrava la salud, porque el fruto madurado por fuerza, o el exceso de funciones, desvía las destinadas a producir la vida, convirtiéndola en una fuente de malestares psíquicos, y debilitamiento orgánico. La moralidad sufre, porque fuera del amor, todo lo demás es una perversión cerebral desde que por un lado ven los jóvenes que le enseñamos castidad, sacrificio, heroísmo, idealismo: y por ofro el Estado que permite esta institución les dice-aquí tengo casas de citas y como yo las reglamento y autorizo debe ser útil y benéfico que ustedes aprovechen de este beneficio que he instituido. Como tengo inspectores que vigilen, y médicos que asistan a las heridas, claro es que ustedes no serán infectados, y como no les pongo a ustedes coto. entren cuando deseen, a toda hora.-Este es el contrato establecido entre el Estado y el desgraciado crédulo que saldrá de esas casas, alcohólico. contaminado por alguna de las enfermedades sociales, deshecho moralmente al conlundir el amor con el libertinaje, huyendo de la idea grandiosa de formar un hogar. La ciencia ha probado, que la continencia, no enferma a nadie. y que iguales abstenciones deben tener los jóvenes. como los que exigen de las niñas. antes del matrimonio.

Aumenta los crimenes, es el centro donde se urden las maldades y atentados, las seducciones de nuevas meretrices incautas. De ahi salen las patronas a los campos, o ciudades a contratar jovencitas pobres e inocentes.

Lejos de restringirse, se acrecienta el número de las asiladas por la facilidad en establecerse. por la costumbre que ya tiene el público de ver esas casas proporcionadas por el Estado, por que habiendo gran demanda de mujeres habrá gran oferta de prosélitas.

No sólo no se hace control del alcohol. sino que se abusa de él. como ha acontecido en los Estados Unidos, es en las casas de tolerancia donde se viola la ley.

Prevenir los atentados contra las mujeres honestas porque existen estas casas de tolerancia, es un argumento tan ridiculo. como decir que el robo debiera permitirse a ciertos granujas para que los honrados no sean ladrones.

Tampoco evitamos, al reglamentar la institución, que las mujeres de ese gremio vivan acorraladas, lejos de eso, las vemos más airosas y desafiantes circular por todos los ámbitos de la ciudad y aun en los lugares públicos como cafées. 
tiendas, etc. En Santiago por 500 reglamentados, existen libres más de 3.000 clandestinos.

Pero el bluft llega al colmo, cuando nos dicen que con asilar reglamentadas se evitan las enfermedades venéreas, cuando es precisamente, que por ellas aumentan. En la costa Barbary de San Francisco de California en 1917, el 97\% de las mujeres públicas se encontraban infestadas. En Baltimore el $96 \%$. En la aldea de Pottsville, habia tres casas de meretrices con un total de veinte niñas, y todas con certificado médico de estar sanas: sin embargo. la investigación ante un tribunal de justicia que delegó en un perito técnico. sus lacultades, de las veinte había 18 enfermas. Una casa tenia tres mujeres únicamente, y ese día las tres habian recibido visitas de 49.37 y 28 amigos; las tres estaban con sifilis.

Esfas mujeres adquieren siffilis y blenorragia, y adquieren además alcoholismo. anormalidad psiquica. demencia o locura.

No se aminora la institución del vicio. porque siendo reglamentada y protegida, va con soltura y seguridad a ejercer su profesión. sin trabajar, y atrae otras incautas.

La despedida de soltero. por banquete que se ofrenda a Baco. termina con ofrendas a las Venus públicas, días antes de la boda. contagiando el alma y el cuerpo del futuro ideal de una virgen sana y púdica.

No se evita que el degenerado se corrija frecuentando los lenocinios, porque justamente, su caracteristica es huir de la mujer, y no es regeneración caer de un exceso anormal a un exceso sexual. Estos se corrigen con psiquiatras, porque la anomalia hereditaria o adquirida se cura: pero por psicoterapia. no con corrupción.

La Liga Americana de Higiene Social, declara que los que defienden este negocio son: $1 .^{\circ}$ los dueños de lenocinios, gerentes. calstens, queridos. que viven de ellas y las explotan. porque el amor es ley tan universal. y aún estas desgraciadas tienen un ideal. un amante; pero éste no siente por ellas otro deseo que el de acaparar su dinero. $2{ }^{\circ}$ Los guardianes que reciben alimento y propinas de noche. $3 .^{\circ}$ Los propietarios. que en vez de ganar por arriendo de su casa $\$ 23$. reciben $\$ 100$. Son defendidos por algunos políticos que obtienen dinero y gajes electorales de los patrones de las casas de tolerancia: son favorecidos por las mismas mujeres que no son capaces de ganar su vida en otra forma; no serán combatidos por municipales que reciben votos de ellos, de inspectores, y de todos los que viven por existir este negocio. Por fin los que sostienen que este es un mal necesario no convencen sino a los sugestionables que en el reino de Dios no son pocos.

Los ejércitos europeos durante la guerra, a pesar de la reglamentación rigurosa de la prostitución. se llenaron de sífiles, excepto los soldados de los Estados Unidos, que no aceptan meretrices, y que además fueron obligados, por sus autoridades. a presentarse a oficinas de desinfección. cada vez que volvían a los cuarteles.

El ejército americano ensayó todos los sistemas para atacar las enfermedades venéreas, y el General Pershing llegó a la conclusión que sólo se concebía una profilaxia eficaz; la abolición de la tolerada institución que $\mathrm{P}_{\text {io }} \mathrm{X}$ denominaba el comercio patentado de carne humana.s Se trata de saber. si lo que hay de más 
venerable, de más sagrado, es decir. la dignidad de la persona humana, continúa siendo, o no, menospreciada envilecida por seres de nuestra especie, de nuestra sangre y ésta legalmente, reglamentariamente con el concurso de la autoridad.

Los otros consejos de profilaxis antivenérea son: Diagnóstico, análisis y tratamiento gratuito. Tratamiento obligatorio de todo individuo durante la época en que es contagioso. Declaración obligatoria de todo médico que trate a un venéreo. sin dar a conocer el nombre del enfermo. especificando detalles de la enfermedad. Sanción penal contra el que contagia. Certificado de salubridad, antes del matrimonio. de ambos contrayentes.

Educación del pueblo en enseñanzas graduales en los mismos Dispensarios sobre los peligros de las enfermedades sociales, ayudada con cuadros, pinturas. afiches y cinematógrafos.

Combatir a los charlatanes que ofrecen tratamientos, que no tienen base. y a los farmacéuticos prohibirles el expendio de medicamentos que se ofrecen para combatir estas enfermedades.

Propagar el expendio de profilácticos, para los que no hayan podido contenerse, en todo Dispensario, y abaratar su producción.

Evitar la llegada de emigrantes enfermos.

Arrojar del pais a los tratantes de blancas, proxenetes, calstens extranjeros, y castigar a los nacionales, a los dueños de casas de cita.

Además de los Dispensarios que vamos a establecer, estimular los que tenga la Beneficencia, Municipalidades, la fuerza armada, ferrocarriles, etc.. en los que cada enfermo recibe personalmente la enseñanza que prevée y moraliza.

Tener anexo a toda Maternidad un Dispensario para las madres e hijos enfermos, y en los que ellas junto con tratarse, orientan su vida y aprenden a cuidar sus niños.

Establecer el tratamiento ambulatorio de los afectados de los campos, dependiendo del Dispensario de su Departamento, se da igual instrucción personal.

Hospitalizar toda meretriz mientras sea contagioso. y a todo soldado y marino en el mismo estado.

\section{3.er TEMA. CURAR LOS ENFERMOS. CAMPAÑA ANTI-VENEREA.}

Para tratar el tercer punto del problema venéreo, es menester pasar una revista de lo que debemos conocer como enfermedades venéreas.

La Blenorragia o Gonorrea, que llamaremos la plaga azul, es una enfermedad muy contagiosa causada por el microbio llamado Gonococus, vive en forma de secreción en ciertas secciones de los órganos creadores de ambos sexos. Se sabe que cuando esta enfermedad se desarrolla, que es a los 8 dias después del contagio, es muy difícil prever cuándo terminará. Pero bien dirigido el tratamiento, sanan lodos.

Es tan común, que ya no asombra a la humanidad, y tan peligrosa cuando toma complicaciones, que se puede decir, que en la mujer es más grave 
que la sífilis. Corta la vida, porque la infectada en sus órganos prolundos, no puede pensar en tener hijos, y si avanza el mal, llega a ser mutilada hasta perder su sexo. El médico sabe hoy evitar estos desastres, cuando se sigue sus prescripciones.

En el hombre, si se complica, puede detener las funciones de la reproducción. En ambos sexos ataca a menudo la vejiga, los riñones e invade la sangre, produciendo falsos reumatismos, gravísimas artrítis, en todas las articulaciones, ataca la pleura, el corazón y las meníngeas cerebrales.

Se puede decir, que cada vez que una mujer es atendida por un ginecólogo, o un hombre, por un urólogo, es por complicaciones de la plaga azul.

Y si esta enfermedad la desarraigamos del país, como lo esperamos, si se adoptan los medios que aconseja la ciencia, no existirian ni las clases de Ginecologia, ni la clase que yo proleso.

El contagio de esas secreciones es frecuente en los ojos, a donde llegan por las manos del propio enfermo, produciendo lesiones graves y aún la ceguera.

Pueblos enteros hay en Oriente y Egipto que tienen oftalmias gonorreicas sostenidas con mayor cronicidad por las arenas del desierto.

Pero también los inocentes, los niñitos, nacen con sus ojos infectados cuando al nacer recogen de su propia madre secreciones de esta indole, y con tal gravedad, que las cegueras son más comunes por esta causa que lo que se supone. En las maternidades del orbe entero, se acostumbra a dejar caer en los ojos de los recién nacidos, soluciones de nitrato u otras sales de plata; es preferible hacerlo así, antes de exponer al niño que recién llega al mundo a no verlo jamás.

Hay más todaviá, niñitas nacen con sus órganos intimos infectados por esta plaga que afecta a sus madres y podemos decir tioy. que no hay ninguna genitalitis en virgenes o casadas que no reconozca este origen.

La madre o empleadas afectas, pueden usar los utensilios de su toilette para asear estas niñitas e infectarlas con un mal que puede ser su desgracia para toda su existencia.

La Blenorragia tiene una marcha larga; pero bien dirigida la curación, se sana bien, y definitivamente; a veces establece una complicación gravísima. Es muy frecuente en Chile que este mal se complique, por ser mal curada. por ser propagada al interior con tratamientos inadecuados, suministrado por ignorantes, entre los que descuellan las enfermeras. las matronas, los practicantes, los farmacéuticos y los amigos de quienes se confian los enfermos.

No creo que haya otro país en donde los farmacéuticos, que no tienen ninguna preparación médica, puedan hacer el papel de doctores, y que el pueblo tenga tanta fe para buscar en ellos sus consejos, ni donde las matronas se atrevan a ser ginecólogas y las enfermeras puedan actuar fuera de la atención de un doctor. Inyecciones cáusticas, intervenciones sépticas, manipuleos no científicos, dan las complicaciones de las funciones más respetables y sagradas.

pero lo que no es de asombrar, es saber que todo hombre que ha mantenido relaciones ilicitas. adquiere tarde o temprano la blenorragia. y como los hombres son los que dictan los hábitos sexuales, y han enseñado mal a la juventud, dicién- 
doles que ellos tienen derechos que les niegan a la mujer, resulta que la inmensa mayoria mantiene tales relaciones. Sólo se libran los abstinentes y los que tienen una educación científica en estas materias.

La blenorragia invade a nuestro pais, y ella puede ser desarraigada absolutamente de nuestra raza.

Introducido este flagelo en la mujer, transforma su cuna de creación en un cementerio vivo: impide la procreación; y avanzando hacia sus entrañas más sagradas. le quita su carácter femenino, la hace asexual, y mata los tónicos de su vida, sus secreciones endocrinas que le dan su alegria, su viveza. su intuición, sus atractivos femeninos, sus caracteres de mujer; porque la mujer es, lo que son sus ovarios.

\section{¿Cómo extirpar este mal?}

Educación, continencia, y certificado de sanidad absoluta antes del matrimonio: mejor sería el certificado moral de su propia conciencia. Mucho puede hacer el consejo del amigo honrado, del médico riguroso, del sacerdote y de una ley especial.

El ejército americano, castigaba a aquel que aparecía enfermo, porque no habia ido a las estaciones profilácticas a desinfectarse. En la actualidad. en Paris el doctor Gauducheau ha inventado una pomada higiénica. El mismo en el Instituto Pasteur se hirió un brazo expresamente, se aplicó secreción con espiroquetes sifiliticos, previo un análisis de su sangre que resultó pura, y después de una hora de haberse contagiado experimentalmente, se aplicó esta Pomada, y no obtuvo ningún brote. Ya Menchnikof el gran ayudante de Pasteur, inventor de la pomada con calomelano, había inoculado sifilis a dos chimpancées, en lós párpados; pero a uno le frotó la pomada y no prendió la enfermedad, y sî estalló en el otro.

La plaga roja, la sífilis, la lúes como se le llama, es una enfermedad general producida por un espiroquete que se mueve como un tirabuzón, rápidamente; que pulula y se multiplica de una manera pródigiosa, y que, como el gonococus, no vive sino en el ser humano. ellos.

$\mathrm{Si}$ se ha conseguido cultivarlos en animales es artificialmente, y viven mal en

Entra en la región contagiada en forma de una peladura insignificante después de 10 días, produciendo en seguida una úlcera sin dolor. endurecida, por lo que se denomina chancro indurado, o sifilitico. o esclerósis inicial, cubierta de millones de espiroquetes o treponemas.

Empiezan a invadir el organismo en donde se sitúan, viviendo en la piel, en los ganglios y entre las células de todo el organismo: llevados los microbios por el torrente circulatorio, van al corazón, al cerebro, a todas partes. Viven de los tejidos, y dan al plasma una secreción especial que modifica a fondo la composición de las proteinas liquidas normales de la sangre de donde las células extraen su alimento.

Si de este plasma sanguíneo, envenenado, extrae su alimento la célula cerebral se comprenderá que el individuo afectado. no tiene la mente sana porque la sangre no lo está: de ahí la inmensa cantidad de habitantes de la casa de lo- 
cos, de las cárceles, y de perturbadores de la sociedad en todo orden de ideas y disciplinas. De la sangre de los individuos sanos se forman las secreciones internas, que según sea el órgano:- timo. tiróides, hipófisis, cápsula suprarenal, páncrea, testículos, ovario, ganglios, nodulos linfóideos, y epitelios-así es lo que preside: determinan o el crecimiento del niño, o la nutrición del desarrollo del adulto. o los frenadores del crecimiento excesivo, o los excitadores de la combustión de glucosas y grasas, o bien los que determinan el depósito o reserva de alimentos, los que generan la vida de los nuevos seres, o determinan el tipo masculino o femenino secundarios, la nutrición de las mucosas, etc. En el afectado de sifilis se desarrollan estas grandes lunciones de un modo exagerado o insuficiente, y entonces va a sobrevenir-si no se ha tratado en forma de extirpar los espiroquetes-perturbaciones tremendas e inesperadas que transforman al individuo en una carga social enorme, o mueren prematuramente, o pueblan Hospitales. Hospicios y Manicomios, o engendran hijos que Ilevan la tara hasta los hijos de los hijos.

Las manifestaciones de esta enfermedad ocupan las ramas de todas especialidades que abarca la medicina. No se escapa ni un solo órgano, ni un solo tejido. de ahí es que todos los médicos, sin excepción, deben igualmente ser, además, especialista en Venereologia.

Se cree que la sifilis nació en América y que los marineros de Colón la llevaron a Europa. Es muy posible que las Antillas fueran el centro primitivo; pero con llegar los soldados de regreso de América, se cubrió la Europa entera. Los primeros colonizadores de Chile, traían tanto soldado enfermo, que en 1567, el $5^{\circ}$ médico que ejerció en Chile, el Bachiller Bazán, trataba a todo enfermo de cualesquier sintoma con ungüento del soldado, como se denomina a las pomadas mercuriales. La había en tanta cantidad que dicho médico la usaba a destajo, y hubiera o no manifestaciones de sífilis, hasta que las autoridades se vieron obligadas a llamarle la atención y obligarlo a no ser exagerado.

La sifilis no marca la cara o el resto de la piel con las lesiones que cree el vulgo que sirven para reconocerla. Si hay lesiones cutáneas, son fugaces y ceden pronto al tratamiento, esto por lo que respecta a Chile. En otros paises las marcas visibles en el rostro, cutis, son más frecuentes.

A más de adquirir la esclorósis inicial, la entrada de los espiroquetes vienen depresiones de la salud, ligeras roseolas fugaces, erupciones de la piel, invasión de los ganglios próximos y de los ganglios del resto del cuerpo, úlceras en las mucosas, en especial en la garganta, labios y lengua, caída pasajera del pelo, etc. Este es el periodo secundario.

La síflis que no ha sido curada en el período secundario, ataca todos los órganos, todos los tejidos y pasa a constituir el período terciario, el de la cronicidad. el de los desastres inesperados. Pasemos una ligera revista de las afecciones más conocidas y que en una gran proporción se atribuyen a ella.

La sífilis es la más grande de las comedoras de cerebro.

En el sistema nervioso, tejido noble que preside todas las funciones y la coordinación de las propiedades de los tejidos, puede presentarse en el período 
secundario, en forma de meningitis, psicosis, mielitis aguda, neurorecidivas, enfermedad de la sangre, etc.

Si este mal quedara limitado a los enfermos por tanto tiempo, ya era una enfermedad grave, pero desde que un enfermo engendra un nuevo ser, éste toma su nutrición de la sangre de su madre, (sangre infecta por su esposo) y lo alimenta con sustancias sanguineas alteradas por los espiroquetes, nace el niño infectado con estos microbios que es lo más común, o puede nacer debilitado por toxinas únicamente.

La sifilis es la más gran productora de muertes antes del nacimiento, la causante de la inmensa mayoria de los abortos, y la primera causa sin duda de la gran mortalidad infantil, y del estado enfermizo de los que continúan viviendo.

El niño nace raquítico, inapetente a la vida, muy difícil de cuidar, se atacan de todas las epidemias reinantes, cualesquiera que ella sea; es un pobre terreno en el que prende fácilmente la tos convulsiva, la alfombrilla, las pulmonías, las perturbaciones gastro intestinales. Puede nacer defectuoso, sordo-mudo, con labio leporino, con la bóveda del paladar abierta, con lesiones cutáneas diversas, pénfigos en la planta y en la palma, con lesiones oculares, o de los oídos, en fin, con toda clase de estigmas, parálisis, huesos deformados, etc., etc. Pero estos sintomas visibles son los que menos se observan, pues sólo son reconocibles en un $20 \%$.

Quedan pues $80 \%$ de niños de cada 100 nacidos de padres enfermos, que no tienen sintomas, que pasan desapercibidos, que se les cree sanos. Esto es lo grave, y nos lo revela el análisis de la sangre sólo en nuestros dias, anteriormente se les creía enfermos de otras enfermedades, del cerebro, del corazón, de los pulmones, de las vísceras, etc., etc.

La sífilis en cualquiera forma es absolutamente curable, pero reconocer su existencia, era difícil, hoy no se tiene dudas.

La sifilis infantil precoz, cuando se la reconocía se la trataba y curaban, y cuando no se diagnosticaba. morian bajo el nombre de otra enfermedad. La hereditaria tardía, que puede estallar desde los 10 años y durante toda la vida, se reconocía por la deformación dentaria, por las perturbaciones en los órganos de la vista, oído u olfato, en las deformaciones del cráneo. del paladar, de los huesos y con esto llenábamos los libros, satisfacíamos nuestros conocimientos.

Pero desde que Schaudin, botánico, descubrió el espiroquete pálido, y desde que Wassermann descubrió que por el análisis de la sangre se conoce el que tiene o no la plaga, y desde que Ehrlich descubrió el 606 o salvarsan que cura y sirve para hacer el diagnóstico icuánto progreso ha habidol. de tal suerte que hoy, un especialista no puede dejar de conocerla donde ella exista, y no puede dejar de extirparla.

Hace dos años Leredde decía: ¿La sífilis de la primera infancia no se vé en la inmensa mayoría de los casos, no se manifiesta en la inmensa mayoría de los casos, es necesario investigar mucho para descubrirla. Rara vez tiene sintomas. estigmas, no aparece sino en el curso de la segunda infancias. En esta época. son a veces de apariencias normales, con ciertas perturbaciones que hacen decir 
stodos los niños tienen siempre que sufrir enfermedades ligeras, y cuando aparece una nefritis, una bronco-pneumonia, no se atribuye a la sifilis.

Error pues es fundar la ausencia de sífilis en los niños, por la ausencia de los sintomas que se creían clásicos, como grande es el error si quieren fundar el diagnóstico en la rebusca de ella en los padres, cuando sabemos que el $20 \%$ de los hombres y el $40 \%$ de las mujeres que están infectadas lo ignoran, y también cuando los padres niegan haberla adquirido creyendo deshonrarse o ser marcados con el estigma del menosprecio al confesar su enfermedad. El padre que la tiene. jamás debe ocultarla, y aún dejar una carta lacrada en su escritorio, para que sea abierta, si él llegara a faltar. El está protegido por el secreto profesional, secreto que cubre su honor y el de su familia, el que jamás puede violar un médico. aún requerido por la justicia, pues las leyes morales están por sobre las civiles, a pesar que sea relevado del secreto por el propio cliente, porque el secreto ya no es el del cliente sino del médico.

La sifilis despuebla más que cualesquiera otra causa; a la enorme mortalidad y morbilidad producidas por la sífilis adquirida, hay que sumar la mayor morlalidad y mayor número de enfermedades de la sifilis hereditaria.

Este es un tremendo problema social, que no necesita espera y que nos obliga a resolverlo cuanto antes, porque el primer deber de los poderes públicos es procurar la salud de los habitantes, el segundo dar educación que sirve cuando se ha resuelto el primero.

Se calcula prudentemente que el $10 \%$ de la población de Francia está infectada de esta enfermedad; en nuestro país, donde no existe profilaxis antivenérea y el contagio es tan frecuente como nulas las precauciones, donde la ignorancia sobre el problema sexual es generalizada no es prudente reconocer que la población infectada sea menor de $10 \%$.

Cuatro millones de habitantes más o menos nos dan $400 \mathrm{mil}$ enfermos de sífilis, cifra superior a toda otra morbilidad existentes en Chile. Esta cifra es terrible, pero está lejos de ser exagerada.

Cualesquier otro cálculo que hagamos sobre el número de enfermos no puede tener base cientifica, nadie los ha contado, ni sería posible en el estado acfual de nuestra organización, porque no se puede esperar se inscriba el verdadero nombre de esta enfermedad, y hay que leerla en las defunciones con el nombre de parálisis, angina, pneumonias, úlceras digestivas, afecciones cerebrales. nefritis, etc., etc.

Quedémonos moderados en nuestros cálculos y digamos stenemos al frente 400 mil sifiliticoss. Esta cifra es espantosa porque abandonados a sí mismo. pronto serán redoblados y antes de 10 años sería escaso el que se hubiera librado.

Reflexionemos, apretemos los puños y pasemos al optimismo de la ciencia que nos dice puestos a la obra en una lucha antivenérea por 10 años podemos desarraigar la sífilis de nuestra Patria.

¿Cómo realizar este prodigio?

El enfermo de sífilis de marcha común se cura por medio de neosalvarsan, 
inyectándolo dentro de las venas, una vez por semana, y elevando la dosis gradualmente hasta completar seis semanas. Sigue un mes de reposo y se vuelve a comenzar otra seis semanas para alternar con descanso, y así por el espacio de 3 años. Esto está sujeto a las modificaciones que exigen la edad, el sexo (porque la mujer necesita menores dosis). la robustez, la intensidad del virus, etc.. etc. En Chile esta enfermedad tiene apariencias más benignas, vedadas, por consiguiente. más traidora porque en la edad madura se presenta produciendo lesiones orgánicas serias de igual intensidad que las que se manifiestan en los demás paises.

En la lucha contra la plaga roja es menester que los médicos tengan igual concepto sobre el tratamiento. Se debe obligar que todo médico que aspire cualquier puesto en los Hospitales u empleo fiscal tenga un diploma especial de haber seguido un curso de Venereologia y Serologia. Así se evita la anarquia que reina con respecto al tratamiento tanto aquí como en el extranjero.

Antes del descubrimiento del 606 se empleaba exclusivamente el mercurio. Su empleo es muy largo, casi diario, y a veces peligroso e inferior al citado. No extirpa por sí solo la enfermedad a punto de sostener una reacción de Wassermann durante un año a las dosis que tolera un enfermo: porque la dosis qne seria efectivamente curativa, 4 centigramos de biyoduro de mercurio, o equivalentes. suficiente para curar, aplicada por 3 años, no es tolerada por todos los individuos. Sin embargo no podemos prescindir del mercurio en la primera infancia, en enfermedades que han tomado una marcha especial o en los resistentes al arsénico.

Se llega, pues, a la conclusión que los afectados de sífilis de marcha común pueden ser curados radicalmente en 3 años. Si de los 400 mil habitantes atacados de esta enfermedad, acudieran a un tratamiento 200 mil durante los 3 primeros años, este número entraría a la población sana. Los 200 mil restantes serian tratados en un segundo ciclo de otros 3 años, es decir. los recalcitrantes que no hubieran todavia entrado al tratamiento, y que buscarán el Dispensario sólo después de la propaganda llevada por los Telizmente curados.

¿Por qué existe tanta sifilis desconocida?

Porque la entrada de ella puede haber sido por una lesión microscópica, una erosión inapercibida, cosa que sucede muy frecuentemente en la mujer.

Porque puede haberse ocultado bajo las apariencias de una simple gonorrea.

Porque puede desarrollarse, sin darse cuenta, con el producto de la concepción.

Porque no hay ley, que obliga a los que contraen matrimonio, que hagan análisis de su sangre, para que en caso de obtener reacción positiva se traten hasta extirpar su mal.

Porque no hay concepción exacta de la moral personal, sino que existe un código oscuro de orientaciones. que hace que los enfermos tengan falso pudor y les repugne confesar que están afeclados de una enfermedad que es una verdadera desgracia imprevista, pero que como tal, no debe avergonzarse de ella, como no 
se avergonzaria de la tuberculosis. El sentimiento de desprecio es injustificado, porque si 10 personas honorables han cometido la torpeza de aceptar la invitación del Municipio para ir a casas de tolerancia, y cinco adquieren sífilis, el juicio público declara despreciables a los cinco honorables que han tenido la desgracia de adquirir sifflis honorable y los cinco atacados sólo de plaga azul que curarán en dos meses, esos van a tener patente de buena persona durante su vida. La ignominia no está en tener la enfermedad. Es torpeza creer a las autoridades que son responsables de ellas; ignominias que son atenuadas por la naturaleza masculina impulsiva, poligama, que sólo la contiene la gran educación en los fenómenos de la vida, y la caballerosidad; y se atenúa porque ha tenido la educación del ambiente que acepta las relaciones ilicitas con tal que sean con mujeres comercializadas o con la infeliz proletaria qne desperece por unos cuantos centavos. Pero ese ambiente que tolera, que no prohibe, que permite, excusa y encubre, no aceptaria que fueran sus madres, sus esposas, sus hermanas o sus hijas los objetos de placer elegidos por los incontinentes. Ese ambiente lo estimulan los partidarios de la prostitución, el Municipio que lo reglamenta y asegura la sanidad, el Estado que no pulveriza los focos de infección.

Los Dispensarios municipales y los de la Beneficencia, los de los Ferrocarriles. del Ejército y Marina deben subsistir siempre, aún después de terminada la campaña para exterminar la sífilis del país.

Entre las medidas profilácticas usadas en Francia, existe la profilaxia individual para los que se han expuesto al contagio por medio del empleo de una pomada preservativa. En el informe que pasó en 1921 el doctor Paul Faivre. jefe del Servicio Antivenéreo de Francia, al Ministro de Higiene de Asistencia y de Previsión Social, dá cuenta que con la pomada del doctor Gauducheau, se ensayó en 700 voluntarios de la Marina, bajo la dirección médica, y el resultado coronó las esperanzas que en el éxito de esta pomada cifró su descubridor. Iguales resultados se han obtenido en los 200 mil soldados de la ocupación actual del Rhur.

En Chile no existe una lucha antivenérea. El Código Sanitario dejó entregada a las Municipalidades una de las fuentes de infección; las reglamentadas, pero las mas peligrosas las clandestinas escapan a su vigilancia.

Atacar las enfermedades infecciosas comunes es del resorte del Director de Sanidad; pero atacar a las más graves, a las que producen más estragos, a las que degeneran a la raza y a sus hijos, a esos los dejó la ley como un buque al garefe sin dedicarles ni un solo inciso en el Código Sanitario.

Los hospitales atienden toda clase de enfermedades de pacientes que necesitan cama: pero los sifilíticos rara vez la necesitan, luego no buscan el Hospital, y trafican por los cuatro puntos cardinales llenando del virus a la población sana.

Las enfermerias de ejército. marina, carabineros, policias, tienen igual objeto, para con los enfermos atacados de afecciones comunes, y envian al Hospital a los que exigen un cuidado mayor; pero siendo ellos la fuente principal de contagio y pudiendo ellos ser recluídos mientras pueden contagiar, es menester recomendar a sus autoridades, se inspiren en los elevados ideales que nos obligan a todos los ciudadanos que tenemos alguna responsabilidad, en cualesquier repartimiento público, 
a disponer de todos nuestros esfuerzos, para procurar la salud de nuestros suballernos y evitar la propagación del contagio.

Los Dispensarios existentes en el pais atienden toda clase de enfermos, y se ha probado que la gran concurrencia no permite al médico llegar a un diagnóstico prolundo y a disponer de Laboratorio. Además el número de Dispensarios es muy limitado, y los destinados a las enfermedades venéreas, establecidos en el pais son tan escasos que a penas influyen en disminuir el número de enfermos.

Luchar contra la sifilis es curar.

El Dispensario Antivenéreo es el organismo por excelencia contra la lucha dice Faivre.

El instrumento de la lucha anti-sifilitica no es, y no puede ser otro que el Dispensario, dice Leredde. EI Dispensario de barrio, de radio limitado, con servicio serológico anexo, y destinado a curar y dar dirección moral a los enfermos por intermedio del médico,

Los laboratorios pueden recibir sangre de enfermos lejanos.

Los enfermos con complicaciones que exijan cama serán hospitalizados.

Todo Dispensario existente, de cualesquier origen deben subsistir, pero la dirección técnica debe ser una función del Estado, a fin de mancomunar todos los esfuerzos y uniformar los procedimientos de curación. De otra manera la anarquía en un servicio que va a ser tan grande y tan complejo durante los 3 años de lucha, sería tan perjudicial que mereciera el desprestigio público y ahuyentaría los enfermos.

En los campos que forman la mitad del país, también existen las dos plagas. Proviene del contagio que llevan los jóvenes que van a las salitreras a ganar su pan (allá donde el $75 \%$ de los obreros están infectados. La mortalidad infantil en la Pampa es horrorosa, la segunda generación desaparece. Igual cosa acontece con los que buscan trabajo en los puertos o en las ciudades. Los inexpertos Huasos, músculo de nuestras industrias, escudo de nuestra defensa nacional, trasplantados a las ciudades en la esperanza de mejorar su situación. sencillos, llenos de vida, incautos, sugestionables, amigos del trago, cuando llegan a la Estación de una gran ciudad y el amigo que va a esperarlo, comprovinciano- que ya es un hombre muy sabido, - lo lleva a conocer la ciudad empezando por una cantina y terminando en un lenocinio. El huaso en la flor de la edad, nunca había conocido las grandes facilidades que le brinda el Municipio. Exaltado en su imaginación soñadora. comparte su pensamiento entre la ocupación que ha adquirido y el recuerdo tan grato de la amiga que lo recibió entre caricias y placeres. A qué pensar en casarse, a qué cumplir con la prometida que dejó en el campo, cuando aqui son tan fáciles las niñas, tan elegantes y que no le crean ninguna obligación responsable? A los 10 dias de vivir de desvarios y ensueños amorosos aparece en su cuerpo una pequeña erosión, sin dolor: iel chancro duro, que le ha brindado el ángel de sus pensamientosl con permiso del Municipio. Esta es la primera manifestación de la tra- 
gedia que quizás le va a amargar toda su vida. El amigo le dice: eso no es nada. todos estamos iguales, y el huaso triste. a medio curar vuelve a su tierra. ahora si que cumple su compromiso, necesita una mujer que lo cuide, le procure el reposo que requiere su potente músculo, ninguna enseñanza ha recibido, ni ninguna autoridad se opone a que contraiga matrimonio. Espera su anhelado hijo, vienen abortos tras abortos, al fin viene uno que se rehace con la vida sana del campo, cadáver viviente que más tarde por desaparecer ese hijo víctima de la pneumonia, del catarro intestinal o de ataque cerebral, no le hace pensar que él es el causante de esa desgracia. Nadie le dice que se trate, y en caso de oir este consejo de algún médico que por casualidad haya consultado, no tiene recursos como tratarse, ni establecimientos públicos donde le obsequien la medicina para tratarse, ni laboratorios que le certifique la curación de él, de su mujer y de sus nuevos hijos.

La gonorrea en los campos es la más constante preocupación de los casados.

Distribuyen la plaga roja los conscriptos que vuelven a sus hogares. los guardianes rurales, los carabineros, los comerciantes viajeros, especialmente los faltes, los arrieros. los campesinos que de tiempo en tiempo vienen a las ciudades a traer mercaderias. las pobres muchachas venidas a Santiago a servir a cualquiera casa, las más veces a cantinas, hoteles de tercer orden, a casas de ninguna vigilancia y también reclutadas por las viejas viajeras que con promesas y engaños las conducen a las casas de tolerancia. Otras vuelven abandonadas por sus amantes. llevando infecciones que han contraido.

iCuántas veces en el Hospital hemos recibido confesiones que nos demostraban que las sugestionadas y reclutadas a las casas de vicio. mantenían vivo el amor y la ternura de su hogar: eran seres regenerables!

En Chile el esfuerzo municipal, el de las sociedades, el de la Beneficencia, es muy digno de encomio, pero eso es simplemente una gota de agua en el océano de males.

El Estado Mayor General de la lucha antivenérea, debe ser dependiente de la Dirección de Sanidad, ya que no existe un Ministerio de Higiene, Beneficencia y Asistencia Médica.

He aquí el resumen de un plan para luchar durante 10 afios al exterminio de las enfermedades sociales

Se estima que bastan 3 años para atacar la sifiles de marcha normal.

La población de Chile es 4.000 .000 de habitantes más o menos.

Si el $10 \%$ enferma de sífilis, habrian 400,000 habitantes atacados de este mal; 100 mil buscarán tratamiento sólo desde el $4 .^{\circ}$ año de implantación del régimen de defensa. porque entonces se apercibirán de su mal a causa de la propaganda hecha por los 300 mil en curación, o que la reacción de Wassermann o la sifilimetría descubrirá. La mayoría de estos 100 mil. que ignoran estar afectados, son hereditarios, y con revelar la enfermedad, obligan a sus padres a curarse. 
De los 300 mil restantes atacados. queremos creer que, 100 mil serían tratados por sus propios recursos privadamente, otros en los cuerpos colegiados del Estado: Marina, Ejército. Carabineros, Policías, en algunos Hospitales y Dispensarios. tanto de la Beneficencia como de la Municipalidad. Restan, pues, 200 mil enfermos de sifilis, que urge tratarlos en los primeros 3 años. Tomamos en cuenta que no aumentará nuevos, debido a la prevención, y el individuo ilustrado por la enseñanza que dá a cada enfermo el médico que cura, debido a la profilaxia obligatoria, impuesta a los enfermos de los cuerpos citados más arriba o en los Dis pensarios, y por el abaratamiento de ese profiláctico que previenen el contagio en la primera hora después de la exposición. debido a que se impedirá la entrada al país a todo individuo que arribe con las manifestaciones de la plaga roja, o de la blenorragia; debido a la disminución de las enfermedades venéreas, por reclusión obligatoria de la portadora o del portador en los Hospitales de Beneficencia, o en los Hospitales especiales, y por mayor vigilancia sobre el clandestinaje.

Nuestro cálculo versa sobre 200 mil sifilíticos en el primer ciclo de 3 años. Proponemos:

1.' Una Dirección Central, especie de Estado Mayor, que dirigirá el combate en toda la República, con inspectores de Dispensarios y de Laboratorios. con un plantel de enseñanza de Venereología, que abarca Fisiología. Higiene. Ciencia sexual, Dermatología, Sifilidologia, Vías urinarias, Ginecología, Bacteriologia. Serología; con una sección destinada a instruir con lecciones. folletos, afiches, publicaciones, elc., etc., con una sección Estadística.

2. Dispensarios modelos bajo la dirección de un médico jefe, de un médico serologista encargado de las reacciones de Wassermann, del examen microscópico de los microbios que causan estas dos grandes enfermedades, y de la estadística y de la propaganda, de 10 enfermeras o practicantes perfectamente preparados en la atención de esta clase de enfermos. Los médicos jefes del Dispensario y serologistas deben ser especialistas en Venereología. De estos Dispensarios Modelos existirán 22 en el país: 10 en Santiago, 4 en Valparaíso, 2 en Concepción, y uno en cada uno de los lugares siguientes: Iquique. Antofagasta. La Serena, Talca. Temuco y Valdivia.

3. Dispensarios de $20^{\circ}$ orden, en que el jefe será el médico de sanidad, del Departamento o el de Ciudad, o alguno de los residentes con preparación en la curación de esta especialidad con un sobre emolumento. quien tendrá a su cargo un Serologista: Tacna, Pisagua, Taltal, Copiapó. Freirina. San Felipe, Quillota. Viña del Mar, Melipilla, Rancagua, San Fernando. Chillán, Curicó, Linares, Cauquenes. Talcahuano, Coronel, Los Angeles, Victoria. Osorno. Ancud y Punta Arenas; 22 laboratorios de segunda clase. Pero yo concibo tener un médico sanitario en cada Departamento.

En los laboratorios. se hará la reacción de Wassermann de una circunscripción territorial que le sería asignada.

4. Por fin aprovechando los médicos de las respectivas localidades del país, que a nuestro juicio deben ser elegidos entre los que hubieren seguido cursos especiales de Venereología, habrá 59 Dispensarios de tercer orden en Arica, 
Negreiros, Tocopilla, Chañaral, Huasco, Vallenar, Vicuña, Coquimbo, Ovalle. Illapel, Combarbalá, Petorca, Ligua, Putaendo, Los Andes, Llay-Llay, Calera, Casablanca, San Antonio, Puente Alto, San Bernardo, Buin, Rengo, San Vicente de Tagua-Tagua, Peumo. Chimbarongo. Santa Cruz, Vichuquén, Curepto. Constitución, San Javier, Parral, Chanco, Quirihue, San Carlos. Bulnes, Yungay. Tomé, Nacimiento. Mulchén, Lota, Arauco Lebu, Cañete, Collipulli, Ercilla. Angol. Traiguén, Lautaro, Curacautín, Pitrufquén, Nueva Imperial, Corral, La Unión, Rio Bueno. Puerto Montt, Calbuco. Castro y Quinchao. Total 103 Dispensarios, para todo el país únicamente por 3 años y destinados a devolver 200 mil enfermos completamente curados, que de otro modo iría la mayoría a poblar las casas de Orates, las cárceles o a aumentar el número de bolcheviques.

El gasto destinado a los Dispensarios son elevados el primer año de instalación, mucho menos en el segundo y tercer años. Serán reducidos a la mitad el cuarto año, a la cuarta parte desde el $7 .^{\circ}$ año para dejar establecido definitivamente a contar desde el $9 .^{\circ}$ año. los Dispensarios fijos.

Los 22 Dispensarios de segunda clase mucho menos onerosos, porque serán servidos por médicos que tienen otras atenciones establecidas en los Hospitales de ciudad.

Los de tercera clase costarán mucho menos si se tiene presente que serán atendidos por los médicos residentes. La reducción de Dispensarios después de tres años se impondrá porque el tratamiento sería dado sólo a 100 mil enfermos. El 7. año quedará una planta para atender 50 mil afectados, que aun necesitan prolongar el tratamiento a los rezagados por ignorar el mal y los nuevos enfermos que hubieren sido recientemente atacados.

Ya el $100^{\circ}$ año podrá la República mirar con frente alta ante de las demás naciones civilizadas, habiendo extirpado, desarraigado de su población la sifflis y la blenorragia, y haber dejado reducido sus Dispensarios a un servicio común de sanidad.

Se gastarán, según cálculos numéricos, \$4.192.800 el primer año de trabajo. El segundo y tercer años (descontando los gastos de las instalaciones ascendente a $\$ 1.445,000$ ) el costo sería $\$ 2,747,800$ por año.

El ciclo de $4 .^{\circ}, 5^{\circ}$ y $60^{\circ}$ años se dedicaría a atender a los 100 mil enfermos, demandaría gastos, la mitad del anterior: \$1.375,900.

En los años $7 .^{\circ} .8^{\circ}$ y $90^{\circ}$. se tratarian 50 mil enfermos con gasto de 686 mil 950 pesos.

Después del 9. año la organización estable estaría en relación con los pocos casos que existieran en el pais, y por el resto de los $400 \mathrm{mil}$ enfermos sobrevivientes.

El $100^{\circ}$ año, terminada la lucha contra la sífilis y la blenorragia, la Dirección de Sanidad se encargaría, por intermedio de una Sección reducida, de atender los casos exporádicos, porque es de esperar que la propaganda hecha en los diez años, personalmente a 400 mil enfermos y la de la instrucción sexual de los establecimientos de educación, como la suministrada en las instituciones benéficas, así como la abolición de la prostitución y reclusión de los contagia- 
dos disminuirá el número de enfermos. El $100^{\circ}$ año el gasto no ascendería a 100 mil pesos. En 10 años el Estado ocuparía 16.476.950 pesos.

En el primer año de la lucha antivenérea se gastaría un peso 8 centavos por habitante, lo que no es mucha contribución. El segundo y tercer años el gasto sería de 60 centavos por cada habitante, el $4 .^{\circ}, 5 .^{\circ}$ y $6 .^{\circ}$ años 34 centavos, $7 .^{\circ}, 8 .^{\circ}$ y $9 .^{\circ}$ años 17 centavos, y posteriormente no más de 10 centavos por habitante. Estados Unidos que todo lo tiene hecho gasta 15 pesos chilenos por habitante para toda enfermedad.

Newman, médico jefe del Ministerio de Higiene de Inglaterra establece que la salud y el vigor físico del pueblo son la principal riqueza de una nación. Siendo Chile el país de mayor natalidad conocida, pierde 50 niños de cada 100 muertos de todas las edades.

La duración de la vida en la sífiles en Chile es inferior a 15 años comparada con los sanos.

Veamos ahora la pérdida del Estado en 10 años. Si estimamos que un hombre vale 10 mil pesos en la producción, en Chile, en otros paises se calcula 100 mil. Chile pierde 30 muertos por mil habitantes, es decir 133,333 hombres cada año; si el $10 \%$ muere por sifilis, blenorrogia y sus consecuencias, es decir, 13.333 habitantes por enfermedades venéreas, significaría una pérdida de 133.333 .000 de pesos por año, o bien 1.333 .333 .000 de pesos en 10 años. Además 400 mil enfermos de sifilis rinden $10 \%$ menos de dinero que los sanos. Como 400 mil sanos valen $\$ 4,000.000,000$, el $10 \%$ de menor valor es $400.000,000$ de pesos de pérdida por año, lo que en 10 años es $4,000,000,000$, que sumados a $1,333,300,000$ ya citados dan 5.333 .300 .000 pesos de pérdida en 10 años si se gasta los $16.476,950$ pesos en la lucha contra las enfermedades sociales durante 10 años. Disminuyamos lo que queramos y siempre resultará fantástica la cifra que representa en dinero la pérdida de la riqueza nacional.

Se ha calculado que se puede atender en un Dispensario que tenga dos médicos y 10 enfermeras, 300 enfermos al dia, lo que da 1.800 distintos enfermos en 6 dias, y como el tratamiento dura 6 semanas (con un mes de descanso. se puede atender nuevos enfermos durante el reposo. lo que daría 2.000 enfermos por semana, los mismos que serán tratados durante 3 años, y con 103 Dispensarios que hemos creados, se asistirian 206,000 enfermos, que al fin de ese periodo entrarian sanos a la población del país.

Cuando la enfermedad ha sido curada tardiamente o hay complicaciones tenaces, el tratamiento ocupa dos ciclos (seis años).

La base del tratamiento es aplicar el neosalvarsan.

El mercurio, que es un medicamento útil, para ser aplicado requiere tino, paciencia, y en ciertos casos especiales es irreemplazable, sobre todo si el neosalvarsan no es tolerado por el enfermo.

Esperando la mejor aplicación del bizmuto, y de otros metales pesados en estudio, para tener otra ayuda, preveemos que el tratamiento racional del porvenir será la Seroterapia.

Pero es menester uniformar la aplicación de los tratamientos de modo que 
todos los médicos de la República acepten el mismo criterio y conquistado por la ciencia, que ninguno piense distinto a otro, para no desorientar al paciente ni grabar en el médico un sentimiento de pesimismo. Esto se consigue borrando la frontera de especialistas; todo médico debe ser igual a otro en Enfermedades Venéreas, Ginecología, Urologia, Bacteriologia y Serologia.

El doctor Arturo Vernes dice: -La sifilis no se propaga sino por tontera, ignorancia o apatía, y favorece la difusión del cáncer y de tuberculosis.>

El pánico moral de dar a conocer su enfermedad se puede corregir admitiendo en nuestros Dispensarios toda clase de enfermos, reteniendo a los venéreos, que se estudian y se tratan en salas separadas, y enviando a los enfermos atacados de enfermedades distintas a éstas, a Dispensarios de la Beneficencia o de la Municipalidad, cercano de los cuales deben funcionar estos Dispensarios especiales, que no deben tener ningún título que llame la atención.

El mismo doctor ha escrito: La sifilis no es una enfermedad vergonzosa, sino una enfermedad banal microbiana, que tiene fuentes múltiples y variadas de contagio y a la que están expuestos todos desde la cuna hasta la tumba, y el hecho de quedar indemne es una pura cuestión de suerte., Debemos darles confianza y arrancarles los tormentos y martirios que invaden la mente de los enfermos, y que entristece al pensar que no pueden soportar los gastos de una curación tan larga.

Damos, pues. el tratamiento. los análisis y el medicamento gratuitos para todo el mundo.

La sifilis es curable, pero tarda a causa de los tratamientos actuales que son intermitentes o demasiado cortos.

.Es absolutamente demostrable, dice Vernes, que la supresión de la sífilis del mundo entero no es sino una cuestión de organización técnica para tratar los enfermos y según reglas serológicas precisas.,

DR. EDUARDO MOORE. 